\title{
Spinal lipomas: clinical spectrum, embryology, and treatment
}

\author{
Michael A. Finn, M.D., And Marion L. Walker, M.D. \\ Department of Neurosurgery, Division of Pediatric Neurosurgery, Primary Children's Medical \\ Center, University of Utah, Salt Lake City, Utah
}

\begin{abstract}
$\checkmark$ Spinal lipomas, particularly lipomas of the conus medullaris and terminal filum, are the most common form of occult spinal dysraphism and represent a wide spectrum of disease with regard to anatomy, clinical presentation, and treatment options. These lesions, however, are united by a similar embryology and pathological mechanism by which symptoms arise.

Recently, the treatment of these lesions has generated much controversy, with some physicians advocating surgical treatment for all patients regardless of symptoms and others proposing that surgery be withheld until symptoms develop. The authors discuss lumbosacral spinal lipomas, with particular attention to the theories of their origin, anatomical and pathological features, and treatment options, including a review of current controversies.

(DOI: 10.3171/FOC-07/08/E10)
\end{abstract}

\begin{abstract}
KEY WORDS • conus medullaris spinal lipoma • terminal filum
\end{abstract}

\section{- lipomyelomeningocele - pediatric neurosurgery •}

$\mathrm{O}$ CCULT SPINAL DYSRAPHISMS are a broad collection of malformations loosely grouped together by their common characteristic of being skin covered. Spinal lipomas, in particular lipomas of the conus medullaris and terminal filum, are the most common form of occult spinal dysraphism, and within this subgroup there is a remarkable spectrum of disease with regard to anatomy, clinical presentation, and treatment options. These lesions, however, are united by a similar embryology and pathological mechanism by which symptoms arise.

In recent years, the treatment of these lesions has generated much controversy, with some physicians advocating surgical treatment for all patients regardless of symptoms and others proposing that the surgical option be withheld until symptoms develop. A resolution to this debate cannot be found based on current data, but future observations of the natural history of untreated lesions may offer more insight into the efficacy of prophylactic surgery. Additionally, the rate of surgery-related morbidity has decreased substantially due to acquired experience and newer technologies, making the risk-benefit ratio of prophylactic surgery an evolving and dynamic concept.

The purpose of this article is to discuss lumbosacral spinal lipomas, with particular attention to the theories of their origin, anatomical and pathological features, and treatment options, including a review of current contro-

\footnotetext{
Abbreviations used in this paper: EMG = electromyography; $\mathrm{MR}=$ magnetic resonance; $\mathrm{SSEP}=$ somatosensory evoked potentials.
}

versial subjects. We will focus on lipomas of the lumbosacral area, as lipomas located elsewhere in the spine are uncommon, present with a unique range of clinical challenges, and are likely of different embryological origin.

\section{Classification and Anatomical Description}

Numerous classification schemes and names have been proposed for differing anatomical variations of spinal lipomas. The simplest, and perhaps the most clinically relevant of these, is the division of spinal lipomas into three broad categories: lipomas of the conus medullaris, lipomas of the terminal filum, and "subpial" lipomas (Table 1). The latter group will be mentioned briefly because these lesions are not unique to the lumbosacral region.

Lipomas of the conus medullaris are the most common form of spinal lipoma, comprising between 54 and $86 \%$ of lumbosacral lipomas in several large series. ${ }^{1,2,9,22,37,60}$ This group, being the most variable anatomically and most controversial with regard to treatment, has stimulated the creation of many descriptive subclassifications ${ }^{14,60,78}$ and specific names, which have been used with variable consistency. The following terms have been used with some frequency in the literature.

\section{Lipomas of the Conus Medullaris}

Lipomyelomeningocele. Often used as a general term for all lumbosacral lipomas, lipomyelomeningocele specifically refers to a malformation in which the neural placode 
TABLE 1

Classification and subclassification of spinal lipomas

\begin{tabular}{|c|c|c|c|c|}
\hline $\begin{array}{c}\text { Classification } \\
\& \text { Subtypes }\end{array}$ & Description & Embryology & Presentation & Management \\
\hline $\begin{array}{l}\text { conus } \\
\text { medullaris }\end{array}$ & most common (54-86\%) & premature disjunction & $\begin{array}{l}\text { frequent cutaneous markers } \\
\text { (more common presenting feature } \\
\text { in younger children); neurological } \\
\text { deficit (more common presenting } \\
\text { feature in older children): urologi- } \\
\text { cal, orthopedic, neurological proper }\end{array}$ & $\begin{array}{l}\text { surgical detethering indicated for } \\
\text { symptomatic patients; detethering of } \\
\text { asymptomatic patients is controversial } \\
\text { w/ some recommending watchful } \\
\text { observation; detethering associated w/ } \\
4 \% \text { neurological risk \& } 20 \% \text { local } \\
\text { complication risk }\end{array}$ \\
\hline
\end{tabular}

\begin{tabular}{|c|c|c|c|}
\hline dorsal & $\begin{array}{l}\text { lipoma attaches to dorsal } \\
\text { aspect of conus }\end{array}$ & & \\
\hline caudal & lipoma attaches to caudal & & \\
\hline & $\begin{array}{l}\text { aspect of the conus; may } \\
\text { extend central canal; } \\
\text { nerve roots may course } \\
\text { through lipoma }\end{array}$ & & \\
\hline transitional & $\begin{array}{l}\text { combination of above; large } \\
\text { placode-lipoma interface; } \\
\text { frequently asymmetrical }\end{array}$ & & \\
\hline $\begin{array}{l}\text { terminal } \\
\text { filum }\end{array}$ & $\begin{array}{l}\text { 7-46\% of large series; } 5 \% \text { of } \\
\text { population found at autopsy; } \\
\text { associated w/ disorders of } \\
\text { caudal cell mass }\end{array}$ & $\begin{array}{l}\text { faulty retrogressive } \\
\text { differentiation }\end{array}$ & $\begin{array}{c}\text { may be asymptomatic; may } \\
\text { present } \mathrm{w} / \text { tethered cord }\end{array}$ \\
\hline
\end{tabular}

subpial rare (4\%); can occur in cervicolumbar cord; lies w/in intact dura; infrequently poorly understood associated w/ spina bifida

presents w/ mass effect, rarely tethered cord

\author{
most difficult subtype to detether; short \\ roots may preclude complete detether- \\ ing \\ asymptomatic patients w/ conus in \\ normal position may be managed \\ conservatively; op is indicated for \\ symptomatic patients \& those w/ \\ a low-lying conus; op is low risk
}

lies outside of the spinal canal. A subcutaneous mass of fat extends through a deficient lumbodorsal fascia and lamina to attach to an open neural placode similar in configuration to that of an open myelomeningocele, with the dorsal and ventral roots occupying a similar coronal plane. The lipoma often tethers the cord asymmetrically, leading to rotation of the cord and the unequal development of nerve roots. Rarely, the roots may course through the lipoma, and short roots on the side of the rotated cord may be responsible for tethering..$^{59}$

Lipomyelocele/Lipomyeloschisis. In lipomyelocele/lipomyeloschisis, the lipoma attaches to the open neural placode within the confines of the spinal canal. Lipomyeloceles are about twice as common as lipomyelomeningoceles. ${ }^{78}$

Lipomyelocystocele. A lipomyelocystocele is a rare lesion (constituting $<5 \%$ of lumbosacral lipomatous lesions ${ }^{46,60}$ ) in which there is a dilation of the terminal portion of the central canal into an ependyma-lined cyst. ${ }^{46,57,79}$ The subarachnoid space and cyst do not communicate. Lesions of this type are difficult to identify preoperatively. ${ }^{60}$

Three-Tier Classification. Chapman ${ }^{14}$ proposed a threetier descriptive classification system of conus medullaris lipomas: dorsal, caudal, and transitional. This system has valuable anatomical, surgical, and perhaps prognostic relevance. ${ }^{14,15,52}$

In the dorsal variant, the subcutaneous lipoma penetrates the fascia and posterior elements to attach to the dorsal aspect of a descended conus medullaris (Fig. 1). The conus, dura mater, and lipoma unite along the edge of the neural ridges, and the sensory nerve roots exit just lat- eral to this union. There is often an associated thickened or fatty terminal filum. The lipoma in the caudal variant attaches to the inferior aspect of the conus and may extend into the central canal (Fig. 2). There may be nerve roots coursing within the lipoma, making resection and detethering difficult.

The transitional variant is a combination of the caudal and dorsal types (Fig. 3). The lipoma attaches to the posterior and inferior aspect of the conus and may extend into the central canal. This type of lipoma has a large placode-lipoma interface, which may portend a worse prognosis with respect to surgical morbidity and incidence of retethering. ${ }^{15}$ There is often some asymmetry, with the lipoma attaching more frequently to the left side of the cord and the meninges herniating to the right. ${ }^{60,77}$ In cases of significant asymmetry, the exiting nerve roots may also be markedly asymmetrical, with those on the side of the lipoma being significantly shorter than the onescontralaterally. ${ }^{77}$ These roots can tether the cord by virtue of their length ${ }^{51}$ and can pass through the lipoma, making untethering difficult or impossible at the time of initial surgery. ${ }^{2,60}$ Neurological deficits in asymmetrical lipomas predominate on the side of the lipomatous attachment. ${ }^{52}$

\section{Lipomas of the Terminal Filum}

Terminal filum lipomas make up between 7 and $46 \%$ of spinal lipomas treated in several large series ${ }^{1,2,9,22,37,60}$ and have been shown to be present in up to $5 \%$ of the general population in cadaveric and MR imaging studies (Fig. 4). ${ }^{8,23}$ It is likely that a substantial portion of these lipomas never becomes symptomatic and will not require treatment. These lesions can be truly occult in that they often 


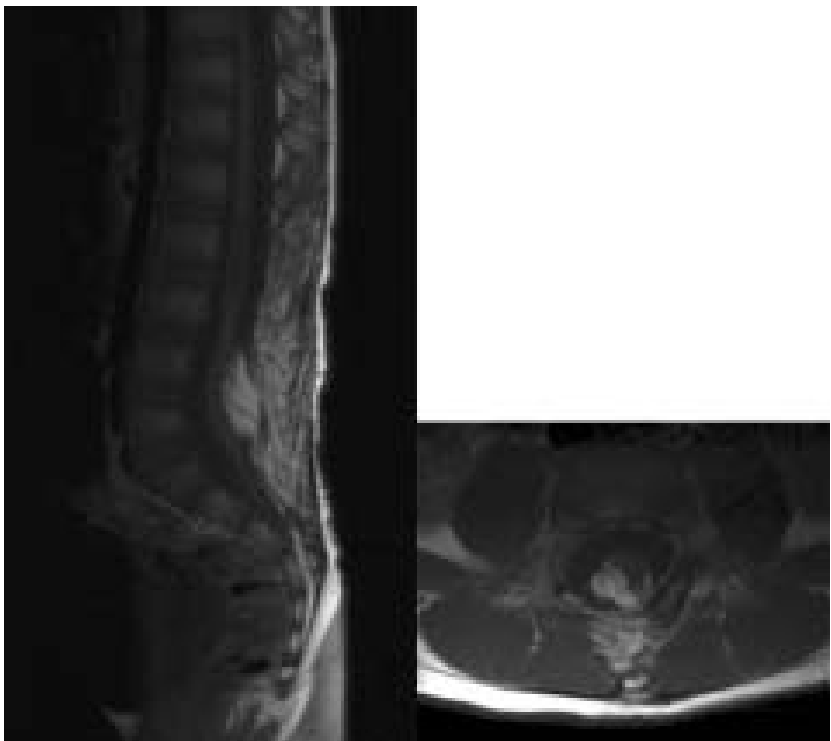

FIG. 1. Sagittal (left) and axial (right) unenhanced T1-weighted MR images demonstrating a dorsal-variant conus lipoma. Note the fatty mass emanating from the dorsal aspect of the descended conus medullaris. The sensory nerve roots are often found exiting just lateral to the junction of the fatty mass and the nervous tissue.

lack the subcutaneous soft-tissue mass and cutaneous stigmata that accompany most conus lipomas. ${ }^{43}$ The lipoma in the large majority of these cases is enclosed entirely inside an intact dura and within the filum, although there have been reports of the lipoma extending through the dura into a subcutaneous mass. ${ }^{60}$ Likewise, although the nerve roots of the cauda equina are normal, there have been reports of the roots intermixing with the filum. ${ }^{7,60}$ Filum terminale lipomas may be a severe manifestation of tight terminal filum, a disorder in which a short, hypertrophic filum coexists with a low-lying conus. The filum in this disorder contains evidence of adipose tissue in as many as $91 \%$ of samples. ${ }^{43}$ These lesions are often seen in disorders involving the caudal cell mass, including caudal regression syndrome, VATER syndrome, and Currarino triad. . $^{53,64}$

\section{Subpial Lipomas}

The final category, subpial lipomas, is unique in that these may occur anywhere in the spinal canal. They comprise about one quarter of all spinal lipomas and approximately $6 \%$ of lumbosacral lipomas. ${ }^{14,78}$ In cases of subpial lipomas, an intact thecal sac surrounds the lesion, which itself lies along the midline and may be of variable size or even multifocal. They have occasionally been reported as entirely intramedullary lesions. These lesions are infrequently associated with spinal bifida. Clinically, subpial lipomas present with symptoms secondary to mass effect, not tethered cord as is the case with lipomas of the filum and conus..$^{60,77}$ Because these lesions do not uniquely affect the lumbosacral region and present a unique set of diagnostic and treatment challenges, they will not be discussed further.

\section{Spinal Malformations}

Several malformations of the nervous system and sur-
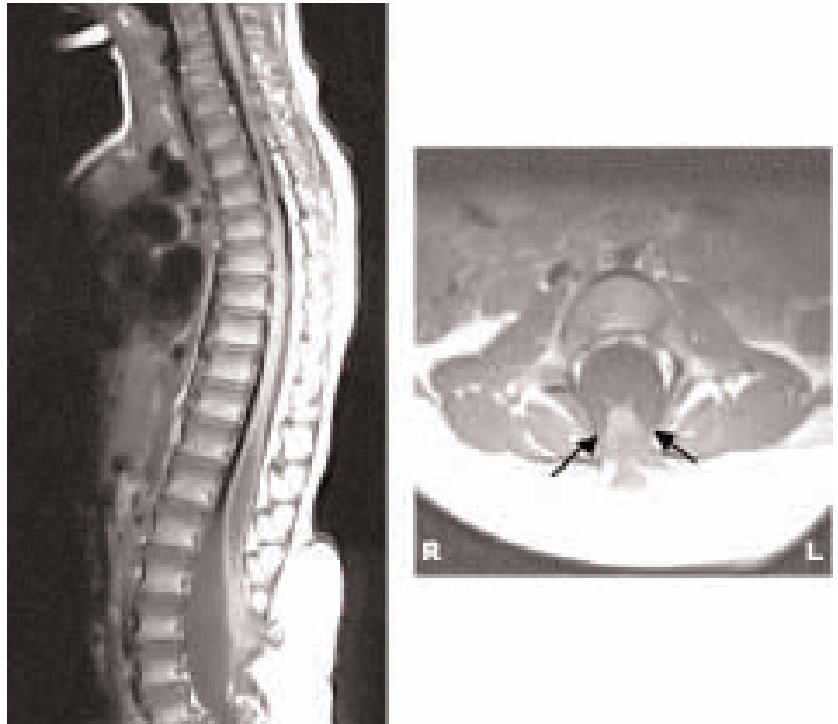

FIG. 2. Sagittal (left) and axial (right) unenhanced T1-weighted MR images revealing a caudal-variant conus lipoma. Note the fatty mass extending from the tip of the descended conus. The fat may extend into the central canal, and nerve roots may be found coursing within the lipomatous mass, making detethering difficult.

rounding tissues are associated with spinal lipomas of the lumbosacral region. Spinal cord abnormalities are nearly universal, with a low-lying conus reported in 72 to $94.8 \%$ of patients with lipomas of the conus and filum..$^{60,84,85}$ As already stated, the nerve roots of the cauda equina may be malformed due to the abnormal position of the conus, especially in cases in which the conus is rotated, leaving the roots on one side of the cord significantly shorter. ${ }^{4}$ Syringomyelia has been reported to occur in 2.5 to $20 \%$ of patients with filum or conus lipomas in various series and may occur more often in patients with transitional-type lipomas. ${ }^{2,60,87}$ Syringes associated with this condition are located in the caudal aspect of the cord and extend over two to three spinal levels on average. ${ }^{26,65,87}$ Patients with syringes tend to present earlier with more significant neurological symptoms. ${ }^{87}$ Other malformations affecting the nervous tissue include diastematomyelia in 9 to $27 \%$ of patient $\mathrm{s}^{38,60}$ and various intralipoma and dural malformations, including dermal sinus tracts, teratomas, dural arteriovenous malformations, and enteric dermoid or epidermoid cysts. ${ }^{58,60,62,65}$

Osseous spinal malformations frequently accompany lipomatous lesions of the spine, with spina bifida occurring in up to $90 \%$ of patients, and they are slightly more prevalent in lipomas of the conus than in lipomas of the filum. ${ }^{60}$ Frequently, the entire sacrum is involved. $.^{50,60} \mathrm{Sac}-$ ral agenesis affects up to a quarter of these patients and is a common finding in the setting of urogenital malformations. ${ }^{60}$ Other observed spinal anomalies include hemivertebrae, vertebral fusion, and scoliosis, which appear to be related to asymmetrical limb length or vertebral anomalies, not neurological dysfunction. ${ }^{60}$

A wide variety of visceral malformations, the most common of which are uroanogenital malformations, is observed in 16 to $27 \%$ of cases. ${ }^{60}$ Thirty-six percent of patients with imperforate anus in one series were found to 

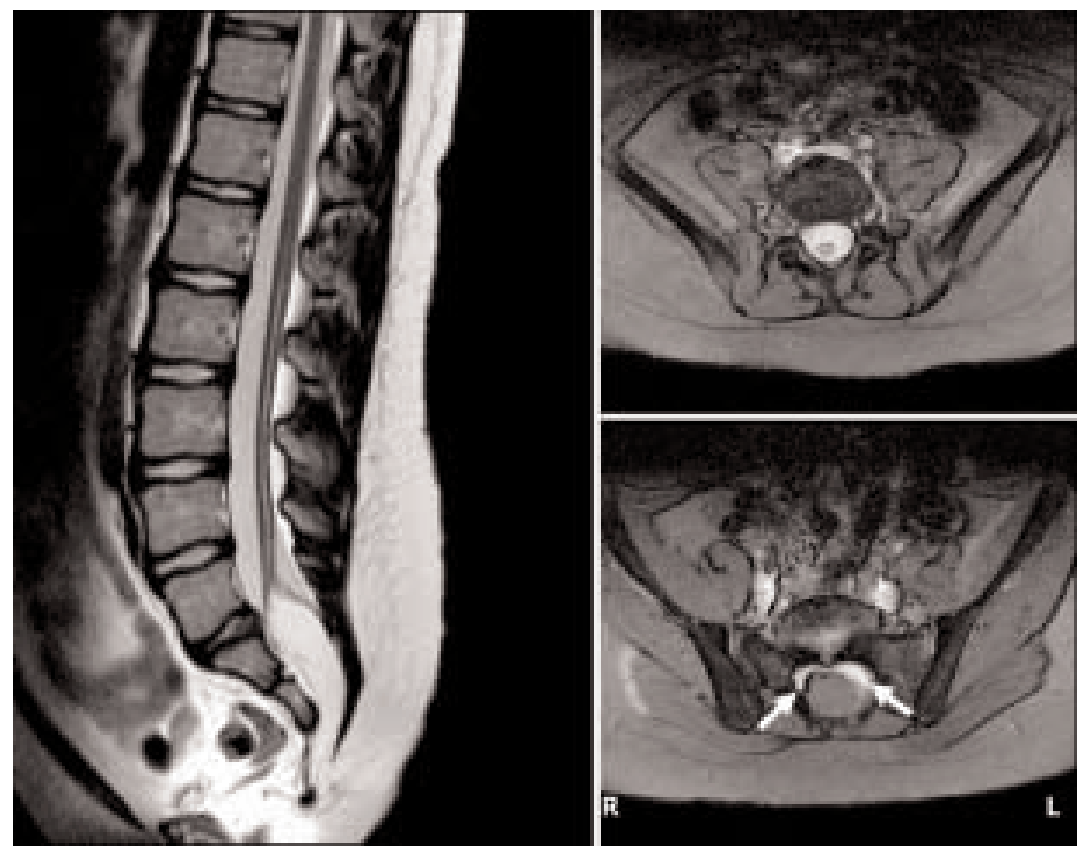

FIG. 3. Sagittal (left) and axial (right) unenhanced T1-weighted MR images showing a transitional-variant conus lipoma. Note the lipoma extending from both the dorsal and inferior aspects of the conus.

have some form of myelodysplasia suggestive of tethered cord, making MR imaging mandatory in the evaluation of all these patients. ${ }^{40}$

\section{Epidemiology and Genetics}

As spinal lipomas are occult lesions, with an unknown number of occurrences going undetected, a true value of their incidence is unavailable. Patients reaching adulthood with undiagnosed lesions and an incidence of up to $5 \%$ on MR imaging and autopsy studies underscore the possibility that this condition may be underdiagnosed. . $, 23,39,70$ The incidence of diagnosed lesions, however, has been estimated to be about $25 \%$ of that of open myelomeningocele defects, or about one in 4000 births, and is associated with an approximately $2: 1$ female predominance. ${ }^{9,30,87}$

Causal factors involved in lipomyelomeningocele formation have been elusive. Folate supplementation has been shown to have no effect in reducing the incidence, unlike its effect in meningomyelocele..$^{48}$ A genetic component has, however, been implicated in their development. Two separate cases of siblings with spinal lipomas have been reported, ${ }^{32,69}$ leading one author to speculate that there might be an autosomal recessive inheritance pattern in these cases. ${ }^{32}$ The authors of other studies of families of patients with lipomyelomeningoceles have revealed an approximately $4 \%$ occurrence of neural tube defects in the siblings of the proband, ${ }^{12,68}$ similar to the 2 to $5 \%$ recurrence rate reported for siblings of patients affected with open neural tube defects. This raises the possibility that the broad array of neural tube defects may be attributable to the pleiotropic effects of a gene or several genes and that different manifestations in this spectrum of disorders may be attributable to different environmental stimuli.

\section{Lipoma Development and Embryogenesis}

Theories on the development of spinal lipomas have undergone significant evolution as knowledge of normal neural development is acquired. A comprehensive review of spinal cord embryology is beyond the scope of this article. Interested readers are referred to the excellent chapters in the bibliography. ${ }^{16,17}$ Current theories are still only speculation, and are thus the center of persistent controversy. Virchow ${ }^{82}$ put forth one of the earliest theories, based on the observation that adipocytes are present in the normal meninges. He speculated that spinal lipomas could result from the hyperplastic overgrowth of these cells. Ehni and Love ${ }^{18}$ refuted this theory, citing the fact that adipocytes were present diffusely throughout the leptomeninges and that their hyperplasia would not account for the predominantly dorsal and lumbosacral location of these lesions. Virchow's theory is additionally unable to explain the development of dysraphism, given that the leptomeninges form after the neural tube has closed. Ehni and Love ${ }^{18}$ in turn proposed that lipomas arise from the same mesenchymal cells that give rise to the spinal cord vasculature. Their theory, however, while accounting for the intraspinal location of the lipoma, also fails to provide an adequate reason for the caudal and dorsal location of these lesions. Additionally, there is now evidence that the endothelial cell lineage diverges early from mesenchymal stem cells, making the likelihood of adipocytes being able to develop from the lineage small. ${ }^{56}$ In contrast, Taubner ${ }^{76}$ had proposed that spinal lipomas could be the product of glial cell degeneration, with the accumulation of complex lipids within their cytoplasm. This theory, however, has been refuted by the results of a more recent study in which the authors demonstrated that adipocytes in spinal lipomas are metabolically and histologically identical to those in normal adipose tissue, not similar to fat found in degener- 


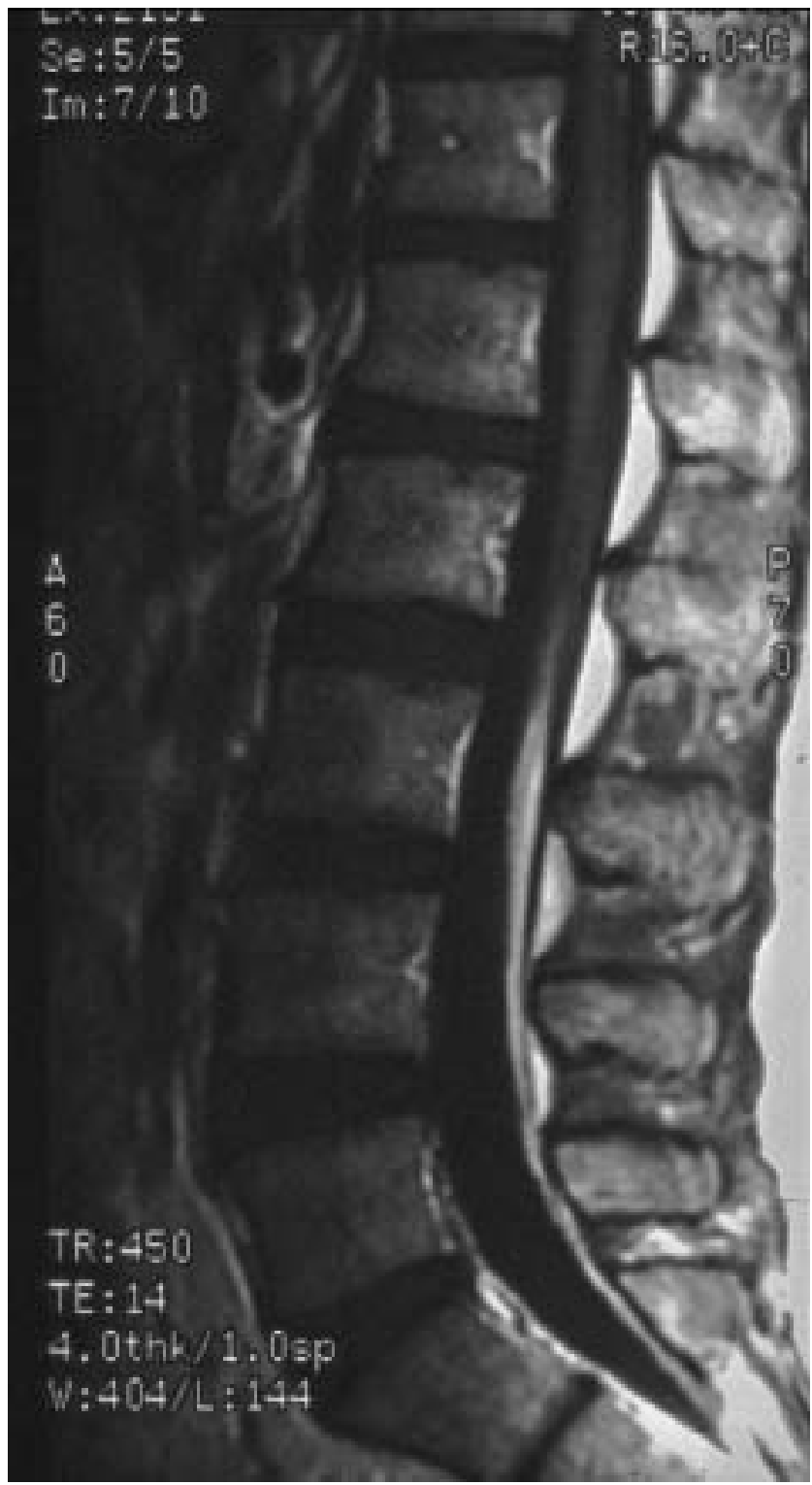

FIG. 4. Sagittal unenhanced T1-weghted MR image demonstrating a terminal filum lipoma. The filum exhibits marked fat infiltration. Note that the dorsal elements are intact.

ative change. ${ }^{21}$ Other theories have postulated the development of lipomas as true neoplasms developing from the meninx primitiva ${ }^{80}$ or as the persistence of cells that would normally disappear during development. ${ }^{35}$

A current theory that accurately accounts for the surgical anatomy of conus medullaris lipomas is that of McLone and Naidich ${ }^{46}$ and Naidich et al. ${ }^{50}$ These authors propose that disjunction, or the separation of the neural tube from the surrounding ectoderm, occurs prematurely, leaving the neural plate open posteriorly and allowing mesenchymal cells to enter this cleft, where they are induced by the primitive ependyma to form fatty tissue. ${ }^{51}$ The anterior surface of the neural tube, where the anatomy is normal, induces the development of normal meninges and vascular structures. The resulting anatomy is such that the dural edge, lipoma, and nervous tissue unite at the lat- eral edges of the placode. This is the transition point in which the anatomy anteriorly has normal tissue planes and structures (that is, pia, arachnoid, and dura) and the tissue posterior is composed of lipoma. Finally, the observation in some series that the histopathology of lipomas often demonstrates the presence of a number of tissues, including muscle, cartilage, and neural tissue, has led some researchers to speculate that lumbosacral lipomas may be a form of teratoma. ${ }^{33,60}$

Theories concerning the development of filum lipomas are more speculative because the terminal filum and distal conus are products of secondary neurulation, a poorly understood process. Current theories on the development of lipomatous lesions in the lumbosacral region center on faulty retrogressive differentiation, with differentiation of pluripotent caudal mass cells into adipocytes. ${ }^{47}$ Such a theory is consistent with the observations that these lesions are less frequently associated with cutaneous stigmata, as secondary neurulation occurs after the closure of the overlying ectoderm, and that they often occur in conjunction with other malformations of the caudal cell mass, such as sacral agenesis and VATER syndrome.

\section{Clinical Presentation}

The initial clinical presentation of the child with a spinal lipoma is variable and depends in large part on the age at presentation. The two main findings that prompt evaluation are cutaneous markers and neurological deficits. Younger children present more often with cutaneous findings, whereas older children often present with neurological problems because patients without or with small and easily overlooked cutaneous markers may escape detection until the onset of neurological symptoms. ${ }^{19,46}$ Tethering of the spinal cord years after initial treatment may cause patients to present again with new or recurrent neurological symptoms.

There are six main cutaneous manifestations of spinal lipomas: 1) midline or paraspinal mass, 2) focal hirsutism, 3 ) dermal sinus, 4) rudimentary tail, 5) atretic meningocele, and 6) capillary hemangioma (Fig. 5). Each of these manifestations has a differing probability of being associated with an underlying malformation; focal hirsutism is the most strongly indicative, and capillary hemangioma is the weakest, the latter being associated with an underlying malformation only about $10 \%$ of the time. ${ }^{77}$ It is also important to note that neonates and infants brought to medical attention have cutaneous stigmata much more frequently than older children and adults and the absence of these signs may lead to delayed diagnosis., 900,87 Approximately $90 \%$ of children with spinal lipoma have at least one cutaneous abnormality, whereas most present with multiple cutaneous anomalies. ${ }^{60,87}$ A subcutaneous mass was the most commonly found anomaly; it consists of a soft, nontender lump that may be located slightly off midline and may deviate the gluteal fold. A coccygeal pit is a common finding that must be differentiated from a dermal sinus track. Coccygeal pits are located overlying the coccyx within the gluteal fold. Although spinal lipomas have been described to occur in association with coccygeal pits, ${ }^{60}$ this association appears to be extremely rare and does not require evaluation in the absence of other clinical findings. 


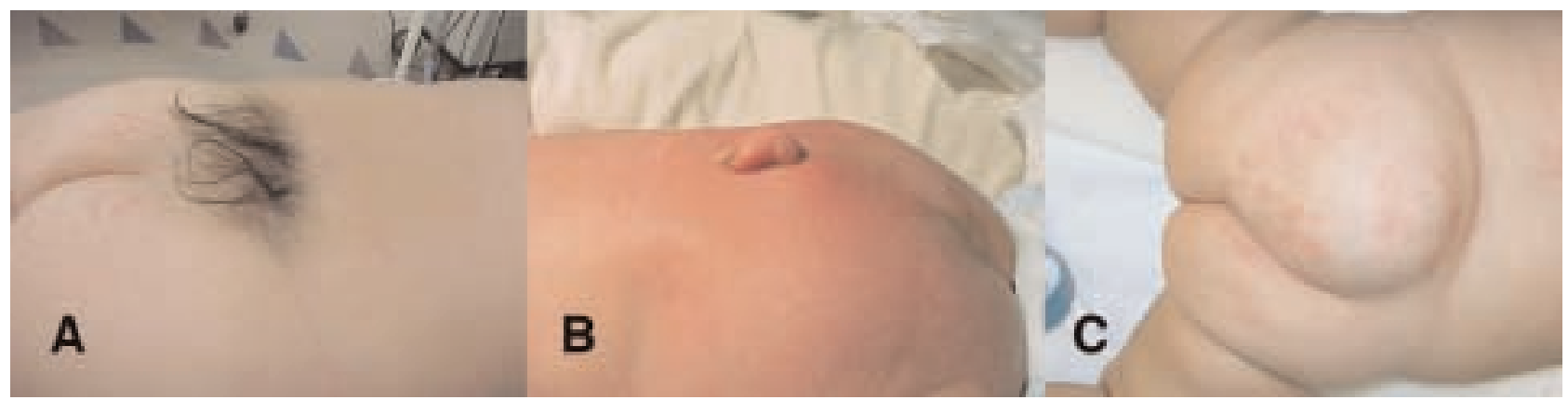

FIG. 5. Examples of cutaneous stigmata of spinal lipomas: focal hirsutism (A); caudal appendage or rudimentary tail (B); and midline subcutaneous mass (C).

Caused by tethering or by the lipoma mass, neurological symptoms affect 60 to $70 \%$ of patients on presentation. ${ }^{60,87}$ There are three main neurological syndromes: urological, orthopedic, and neurological proper. ${ }^{60}$ The neurological sequelae of the disease may be extremely difficult to recognize in infancy. Neurological problems, when present, often affect the lower extremity ipsilateral to the subcutaneous mass, whereas infants with a midline mass tend to be asymptomatic at birth. ${ }^{52}$

The most common neurological manifestation is urological, affecting approximately one half of patients. ${ }^{60}$ This problem is even more common in adults and those with sacral agenesis. Urological problems may manifest as recurrent urinary tract infections, problems with micturition, and incomplete voiding. Often the only abnormality found is an abnormal urodynamic study. Between one and two thirds of infants will have abnormalities revealed by cystometrography and sphincter EMG, where evidence of hyperactive bladder and vesicosphincter dyssynergia are common. 3,47,60,63 Hypoactive bladder, although a more unusual finding, is more often symptomatic. ${ }^{60}$ Urological dysfunction may be reversible if detected early in children, but the prognosis in older children and adults with abnormalities is not as good, with clinical stabilization, not improvement, being the rule. ${ }^{3,63}$ It is important to note that detection of urological abnormalities in infants is exceedingly difficult where bladder hyperactivity and incontinence are physiological. ${ }^{63}$

Urological dysfunction is often the first sign of tethering in older patients who have previously undergone lipomyelomeningocele repair. ${ }^{24}$ As such, careful monitoring is required in all patients with spinal lipomas, especially during their growth years when tethering is more common. Once urological dysfunction due to tethering becomes symptomatic, normal function is unlikely to be recovered. ${ }^{6,30,86}$ Finally, bowel dysfunction is not commonly reported in this patient group but, when reported, constipation is the most common complaint, with stool leakage being rare and usually not due to sphincter hypotonia. ${ }^{60}$

The neuroorthopedic syndrome is present in approximately one third to one half of patients on presentation and consists of lower-extremity deformities, scoliosis, trophic ulcers, and hip subluxations. ${ }^{47,60}$ These deformities are probably caused by imbalance of strength in opposing muscle groups. Lower-extremity deformity is most often characterized by clubfoot, with equinovarus malformation being the most common. Leg length discrepancies are commonly seen in association with hypotrophic changes on the side of the shorter limb, although hypertrophy of leg musculature has been reported. ${ }^{5}$ Scoliosis is present in approximately $10 \%$ of children and may progress in the presence of tethering. Regular monitoring of spinal curves has been recommended, and progression can be halted or even reversed with untethering. ${ }^{11,24,47}$ Finally, it has been proposed that the scoliosis seen in lipomyelomeningocele may be the result of vertebral and limb length abnormalities. ${ }^{60}$

Pain, although uncommon in infants, may be the most common symptom in older children and adults. ${ }^{54,60}$ It is often limited to the lumbar region of the spine and, when it extends to the lower extremities, is rarely radicular in nature. It is often exacerbated by activity, such as stretching, bending, walking, running, or trauma. Progressive pain may herald the onset of cord tethering and is well treated with untethering procedures. Other neurological findings include sensory and motor abnormalities. Sensory and motor deficits are common in spinal lipoma patients. Sensory dysfunction, like pain, is often patchy and nondermatomal in distribution. Motor dysfunction may manifest subtly with alteration of gait or may only be picked up on detailed neurological examination. Any changes in strength or sensory disturbance should alert one to the possibility of tethered cord. Electromyographic abnormalities are detected in almost one half of asymptomatic patients and are universal in symptomatic patients. ${ }^{60}$ When present, signs of denervation are most common in the feet and perineum, can be symmetrical or asymmetrical, and most commonly affect levels below L-4.

Patients with spinal lipomas are at risk for spinal cord tethering and delayed neurological deterioration. Spinal cord tethering may present with an array of symptoms including pain, muscle atrophy, motor and sensory dysfunction, gait disturbance, changes in reflexes, changes in urinary continence, and progressive orthopedic deformities. ${ }^{61}$ Symptoms usually start insidiously; however, abrupt onset of symptoms with rapid deterioration is possible and is often prompted by strenuous activity, trauma, or even obesity or pregnancy. 29,60 The pathogenesis of tethered cord syndrome is likely to involve a combination of factors, including mechanical stress and ischemic changes secondary to hypoperfusion of the tethered cord. Several investigators have demonstrated hypoperfusion of the tethered and stretched spinal cord, which is reversible on release in both humans and in animal models. ${ }^{31,66,88}$ Fur- 
Spinal lipomas: clinical spectrum, embryology, and treatment

thermore, it appears that when the cord is put under tension, most of the deformation takes place in the lumbosacral segments paralleling the amount of impairment of mitochondrial oxidative metabolism. ${ }^{75}$ This correlates with the level of symptoms. Tethered cord release is usually effective at relieving pain in children, but once pain has become chronic in adults, untethering is less effective at giving pain relief. Surgery has variable effectiveness in the reversal of other symptoms, and partial recovery or stabilization is the rule. ${ }^{15,24,74}$ Sphincter dysfunction, once present, is unlikely to improve with untethering. ${ }^{87}$

The risk of spinal cord retethering after initial surgical treatment of the lipoma varies from 10 to $50 \%$, depending on the study. ${ }^{15,24,30,60}$ The most important difference in these studies might be the follow-up time. Colak et al. ${ }^{15}$ calculated the actuarial risk of tethering to be $40 \%$ at the 8 -year mark, similar to that found by Pierre-Kahn et al. ${ }^{60}$ It is apparent that the prevalence of tethering increases with duration of follow-up and that the authors of most series report an initial tethering event approximately 3 to 8 years after the first operation. ${ }^{15,24,30,60}$ This interval may correspond to a growth spurt in children during which rapid growth of the spinal column puts the cord at increased risk of becoming symptomatic, or it may simply be artifactual based on follow-up duration. ${ }^{11,15,24}$ Symptomatic spinal cord retethering can happen well after this 3- to 8-year interval, and patients must be monitored continually. There is a lack of correlation between tethering, age, sex, or dural graft substance. ${ }^{15}$ Patients with transitional-type lipomas, however, appear to be at increased risk of retethering, which may be due to the fact that these malformations tend to be larger, with greater raw surface area to promote the formation of adhesions, and the fact that they are difficult to remove completely. Additionally, patients in whom retethering has occurred once are more likely to experience retethering in the future, indicating that there might be an inherent predisposition to tethering in these patients. ${ }^{15}$ It has been reported by Byrne et al. ${ }^{11}$ that the use of the laser resulted in a decreased incidence of tethering, but this study was not conducted in a randomized fashion and has not been replicated by other authors. [au OK?]

\section{Workup and Imaging Evaluation}

Evaluation of spinal lipomas has been greatly enhanced by MR imaging. Most children who present with characteristic cutaneous findings or neurological syndrome undergo MR imaging, which is highly sensitive and specific for these lesions. Such imaging is extremely useful in planning surgery, showing the anatomy of the lesion with its relationship to the surrounding structures. It also aids in detecting associated malformations, including split cord malformations, arachnoid cysts, meningoceles, and syringomyelia. The T1-weighted images clearly show the lipoma and provide excellent anatomical detail for the delineation of its point of attachment and site of exit through the posterior elements and fascia to connect with the subcutaneous lipoma. The T2-weighted images aid in the evaluation of syringomyelia and meningoceles. The conus medullaris is low lying in the majority of cases and is an indication of tethering in patients with small filum lipomas.
Postoperative MR imaging studies must be interpreted with some caution, because the spinal cord will always look tethered (that is, a low-lying conus and a dorsally displaced cord), and this appearance on imaging alone does not make the diagnosis of clinical retethering. Imaging the patient in the prone position and the use of phase-contrast MR imaging have been employed to evaluate the mobility of the cord in an effort to aid in the diagnosis of recurrent tethering ${ }^{10,28,81}$ but have not proven to be of much use in establishing the diagnosis. Magnetic resonance imaging, however, is useful in the evaluation of a patient with new or changing symptoms to look for the development of a syrinx or expansion of a lipoma, to diagnose other anatomical abnormalities not previously seen (for example, split cord), and to delineate anatomy in preparation for an untethering procedure. ${ }^{15}$

Spinal ultrasonography is a useful modality in the evaluation of neonates and young infants with overlying skin abnormalities. Fat is highly echogenic on ultrasonography, and the presence of intradural fat can easily be detected. Additionally, dysraphic posterior elements and vertebral abnormalities, if present, may be seen. Spinal ultrasonography, being the only dynamic imaging modality available, has also been used to observe cord motion, which is decreased in cases of tethering. ${ }^{49}$ Caution must be exercised in interpreting these findings, however, because the diagnosis of tethered cord remains a clinical one and because the results of any test must be interpreted in the clinical setting.

Plain radiography is of limited value in the evaluation of spinal lipoma, especially in infants with incompletely ossified osseous units. Osseous abnormalities, including widely spaced pedicles, deficient posterior elements, and vertebral and sacral abnormalities, may be evident. In older children and adolescents, plain radiography is useful in the evaluation of scoliosis and spondylolisthesis. Computed tomography scanning clearly delineates bone abnormalities, and computed tomography myelography can be used to evaluate the anatomy of the subarachnoid space and the lipoma but is invasive and provides less information than MR imaging. It is, however, the modality of choice in patients in whom MR imaging is contraindicated. Plain radiography is used to monitor the progression of scoliosis in affected patients

\section{Surgical Management}

The goals in the treatment of spinal lipomas are the protection of neurological function and the prevention of delayed neurological decline. The surgical principles employed to meet these goals include untethering of the spinal cord, preserving neurological tissue, reestablishing normal anatomical planes (such as reconstructing the neural tube), and debulking the lipomatous mass. When considering surgery in the patient with a newly diagnosed spinal lipoma, it is important to consider the type of lipoma and whether the patient is symptomatic. The decision to operate is straightforward in all symptomatic patients and in patients with simple asymptomatic filum lipomas; however, the decision to operate in asymptomatic patients with conus lipomas is controversial.

Although asymptomatic patients found to have a fatty 
filum with a conus medullaris in normal position may be monitored clinically, there is agreement in the literature that patients with either a descended conus or symptoms of cord tethering should undergo surgery. $9,37,60,87$ Although the natural history of filum lipomas is speculative, current evidence indicates that lesions associated with a displaced conus are highly associated with tethered spinal cord syndrome and predispose the patient to the development of neurological symptoms. ${ }^{6,60,87}$ Once symptoms develop, surgical treatment offers the patient an approximately equal chance of symptomatic improvement and stabilization. ${ }^{37,60,87}$ Because the treatment of these lesions is associated with a low complication rate, minimal risk to neurological function, and good long-term results with a low, albeit present, rate of retethering and late neurological decline, ${ }^{37,59,60,72,87}$ it is thought that surgery should be conducted on a prophylactic basis for these patients. ${ }^{6,37,47}$

There is also agreement that patients with symptomatic conus lipomas should be treated, although surgical treatment of these lesions is more complicated and carries a higher risk to the patient. ${ }^{47,60,87}$ Approximately 70 to $90 \%$ of patients undergoing surgical untethering can expect to have their symptoms stabilized, sometimes even reversed. ${ }^{11,37,60,87}$ There is, however, a risk of neurological damage of up to $4 \%$, and a local complication rate of up to $20 \%$ is associated with this procedure. ${ }^{11,60}$ Despite these risks, surgical intervention is clearly favored, as neurological decline will continue without treatment.

The decision to perform surgery in patients with asymptomatic conus lipomas is controversial. Those who favor surgically treating patients with symptoms only have centered their arguments on the unknown natural history of the disease and the fact that surgery is associated with real risks to neurological function and a future risk of cord tethering that has not been demonstrated to be smaller than that of those treated nonoperatively. ${ }^{36,60}$ Pierre-Kahn and colleagues ${ }^{60}$ have perhaps been the strongest proponents of conservative management for this group of patients. In a 1997 review of their surgical experience, they showed that nearly $50 \%$ of asymptomatic patients who underwent prophylactic surgery suffered neurological decline after 5 years of monitoring. This prompted a paradigm shift in their treatment of these cases, in which the asymptomatic patients were treated conservatively and followed with serial examinations ${ }^{36}$ An analysis of data obtained in 53 patients in this group, monitored for an average of 4.4 years, revealed that $25 \%$ of patients exhibited neurological deterioration over this time. Comparing the actuarial risk of neurological decline in this group with that of those who were treated surgically showed no statistically significant difference in outcome. These data, combined with occasional reports of patients reaching adulthood with undiagnosed asymptomatic lipomas, ${ }^{39,42}$ have led some to favor a conservative treatment approach in asymptomatic children. Other authors have been more selective and advocated only observing patients with transitional-type lipomas that, because of complex anatomy, may be more difficult to untether; these may be at increased risk of neurological injury if untethering is attempted. ${ }^{2,13}$

Despite the uncertain natural history of these lesions and the fact that surgery is not without significant risk of complications, most authors support prophylactic surgery in asymptomatic patients with conus lesions. $3,25,27,30,37,45,67,71$ It has been argued that although the true natural history of this condition is unknown, it can be inferred by examining the characteristics of presenting patients. Kanev and Bierbrauer ${ }^{30}$ analyzed patients treated at two different centers and noted that neurological deficits were progressive and logarithmically related to patient age. Other authors have confirmed this trend with the observation that most children are asymptomatic at birth and become symptomatic in the first few years of life. ${ }^{9,11,25,37,47}$ Indeed, patients treated with cosmetic procedures only (that is, debulking of the lipoma without freeing of neural tissue and reconstruction of the dural tube) often suffer neurological deterioration..$^{9,11,25}$ It is therefore reasonable to conclude that the clinical behavior of these lesions is associated with progressive neurological deterioration and that asymptomatic patients are likely to become symptomatic.

This potential for progression is an important consideration in evaluating the need for surgery in asymptomatic patients because neurological symptoms, especially bladder dysfunction and orthopedic deformities, are rarely reversible once present. ${ }^{30,60}$ In the literature, the only patients with normal bladder function and with long-term follow-up had undergone surgery in advance of neurological deterioration. ${ }^{3,20,30,41}$ It is therefore argued that waiting for symptoms to arise exposes the asymptomatic patient to the risk of developing serious and irreversible neurological deficits. ${ }^{9}$

Finally, the risks of surgical intervention appear to be declining in recent series involving newer operative technologies and the refinement of surgical goals. Although nonneurological complications may affect up to $20 \%$ of patients, ${ }^{60}$ most complications are minor and do not contribute to long-term or permanent morbidity, and these complications, including wound breakdown and cerebrospinal fluid leakage, have become more infrequent as surgical techniques have been refined. For example, Kanev and Bierbrauer ${ }^{30}$ reported a greater incidence of wound complications early in the course of their series and attributed this to an overly aggressive debulking of lipomatous tissue, which they modified in later cases. Although the potential for neurological complications of surgery is also a reality, these complications too have become less common, with reports of 0 to $1 \%$ of surgical patients sustaining neurological damage in recent series. ${ }^{11,37}$ These complications may be fewer in asymptomatic patients than in symptomatic patients. ${ }^{11}$ The incidence of delayed neurological decline after surgery in asymptomatic patients is also a topic of scrutiny. Whereas Pierre-Kahn et al. ${ }^{60}$ reported that $46.9 \%$ of their patients developed neurological deficits at 5 years, La Marca et al..$^{37}$ found that only $16.7 \%$ of their patients declined and need a second operation. In this study, the actuarial risk of delayed neurological deterioration at 15 years was 20 and $60 \%$ for asymptomatic and symptomatic patients, respectively. It therefore appears that prophylactic surgery, at least in some series, is safe and effective at preventing neurological decline.

In summary, the decision to undertake surgery in asymptomatic patients with lipomas of the conus medullaris remains an unresolved controversy, with data from different surgical experiences favoring either side of the debate. Ethical considerations preclude a controlled randomized trial to answer this question definitively. A 
Spinal lipomas: clinical spectrum, embryology, and treatment

resolution to the debate, however, will probably be reached as new data are obtained from studies of patients being monitored nonoperatively as they mature and from surgical series using newer techniques.

\section{Surgical Technique}

As previously mentioned, the goals of surgery include the decompression of the neural elements via debulking of the lipomatous mass and freeing of the neural elements from tethering adhesions. The specifics of the surgical procedure vary somewhat depending on the surgeon's preference, and several excellent detailed descriptions have been offered in the literature. ${ }^{6,47,60}$ Here we offer a brief summary of our technique and discuss some controversial aspects of intervention.

We begin by placing the patient in the prone position, making sure that all pressure points are adequately protected, and prepare for a midline incision extending from just rostral to just caudal to the lesion. The caudal aspect of this incision can be curved to one side if necessary to gain better access to low-lying asymmetrical lipomas and to avoid coming too close to the intergluteal cleft. The skin is opened sharply, and a large amount of the subcutaneous lipoma is debulked using scissors and monopolar electrocautery. Use of this method allows rapid and safe debulking of the lipomatous mass. In cases in which the neural placode lies dorsal to the open spinal canal, the use of a more delicate means of debulking (that is, ultrasonic aspirator or laser) might be more appropriate. Care is taken to leave an adequate layer of tissue under the skin so as not to cause devascularization and necrosis.

After the initial subcutaneous debulking, the lumbodorsal fascia is identified and exposed in a rostral-caudal direction until the defect through which the lipoma traverses is found. The entrance is dissected circumferentially around the defect. Next, the fascia is opened in the midline and taken down to the spinous processes, with care being taken to identify any bifid processes or laminar defects. Using the monopolar cautery in a subperiosteal fashion, the paraspinous muscles are then stripped from the posterior elements to the medial facets in preparation for laminectomy, which, depending on the anatomy of the lipoma, is extended one or two levels above the defect or until normal dura is found.

The dura mater is opened in the midline in a rostrocaudal direction and, as the defect is approached, care is taken to avoid cutting the nerve roots because the dura, spinal cord, lipoma, and dorsal roots attach in proximity. Operating in a subdural plane can aid in safely retracting the nerve roots away from this interface. There can be significant adhesions in this region, and care must be taken to lyse these without damaging functional nerve roots. Once the lipoma is freed from the surrounding dura, attention is turned toward releasing it from the neural tissue. Both the $\mathrm{CO}_{2}$ and the yttrium-aluminium-garnet lasers are well suited to this task, and we recommend removing enough of the lipoma so that the neural placode can be reconstituted with pial sutures. If significant lipoma extends superiorly into the central canal of the spinal cord, we pursue limited debulking to relieve obvious pressure on neural tissue but do not pursue complete resection, which may require myelotomy. We next turn our attention toward the filum and, if it is thick, cut it. Finally, when we are satisfied with the amount of debulking and have ensured an adequate release of tethering, we close the neural placode using pial sutures and reconstruct the dura. If insufficient dura is present to create a thecal sac of adequate size, we use a synthetic dural graft (DuraGen, Integra) to reconstruct a generous thecal sac that is then closed in a watertight fashion. We buttress this closure with muscle and fascia to aid in the prevention of spinal fluid leak. If the defect was such that the primary apposition of these layers is difficult or impossible, we advance the muscles and fascia, often with the assistance of our plastic surgery colleagues. Care is taken to eliminate any dead space, and the skin is closed in the normal fashion. We do not use a drain. The patient is restricted to flat bedrest for 48 hours and then is allowed to mobilize.

Some controversy exists over the amount of the lipoma to remove, whether the placode should be closed, whether monitoring should be used, and, whether a syrinx should be drained. There is significant disagreement on the amount of the lipoma that should be removed. ${ }^{25,63,73} \mathrm{We}$ advocate a subtotal removal of the lipoma and remove just enough to close the neural placode. We believe that trying to accomplish a total resection of the lipoma puts the posterior columns at significant risk and does not offer any significant advantage, a view echoed by Pierre-Kahn and colleagues. ${ }^{60}$ Closing the placode is another issue that has been debated. It has been proposed that closing the placode might decrease the risk of retethering by reducing the amount of raw tissue exposed. ${ }^{44}$ Although it is unclear if the incidence of retethering is truly reduced with this technique, we believe that closing the placode makes second operations easier by reconstituting a more normal anatomy. Adhesions noted at the time of repeated operation are often located in the midline directly over the area of neural tube closure, making their lysis much easier than if the entire open placode was adherent.

The use of intraoperative monitoring is also highly variable in reported series. ${ }^{11,44,59}$ Available monitoring techniques include rectal EMG, urethral EMG, rectal and bladder pressure, continuous EMGs, evoked EMG, and SSEPs. To date, a prospective controlled trial has not been undertaken to definitively determine the efficacy of these modalities in avoiding injury in the treatment of spinal lipomas or tethered cord. Rather, anecdotal data from reports and series have lent some support to their use. Paradiso et al. ${ }^{55}$ reported on a series of 44 adult patients undergoing detethering procedures and found that intraoperative monitoring predicted postoperative deficits in both patients so affected and speculated that its use led to the prevention of spinal cord injury in one case. Difficulties encountered with specific modalities included the following: almost $50 \%$ of the patients had abnormalities in preoperative SSEPs, and continuous EMG activity is highly susceptible to nonmechanical factors and may occur during opening or manipulation in up to 18 and $82 \%$ of patients, respectively. Other pitfalls include the time necessary for signal averaging in SSEP monitoring, which may delay the detection of an injury, and the fact that overlapping dermatomes may mask the detection of injury to a specific nerve root. ${ }^{34,55,83}$ While some authors no doubt have found these monitoring techniques useful, we have 
found them to prolong operative times without any clear benefit to the patient and have abandoned their routine use. We do, however, regularly use EMG evoked potential monitoring to confirm the absence of neural tissue when cutting the terminal filum or when attempting to identify nerve roots in a complex lipoma. Like other authors, we have found this technique to be simple and accurate in this limited application..$^{83}$

Finally, the treatment of syringomyelia in association with spinal lipoma has been debated, with some authors advocating draining or shunting of the syrin $\mathrm{x}^{25,26}$ and others advocating detethering alone, ${ }^{60,87}$ citing cases in which the syringomyelic cavities have shrunk without any direct intervention to the syrinx. We have found it difficult to assess whether a patient's symptoms are attributable to the syrinx or to the lipoma and tethering, and thus we advocate draining only large syringes that are thought to have the potential to cause symptoms secondary to mass effect. In cases in which syringes are not drained, it is crucial to obtain follow-up imaging in the presence of continued symptoms. Should the cavity enlarge, we believe that it is reasonable to operate again and drain or shunt the cavity.

\section{Conclusions}

Spinal lipomas are the most common of the occult spinal dysraphic lesions and are composed of a diverse group of lesions with respect to anatomy, clinical presentation, and treatment options. Although much has been learned about spinal lipomas, the influence of genetics and environmental factors in their development and their embryogenesis remain the subjects of conjecture. Even the natural history of these lesions has yet to be fully elucidated. Recent work has, however, contributed to an advanced understanding of their anatomy, which, combined with advances in surgical technique, has led to improved surgical outcomes.

Consensus recommendations can be made regarding the treatment of symptomatic conus lipomas and filum lipomas that are symptomatic of or associated with a descended conus: these patients should be treated surgically. Close observation may be prudent for asymptomatic patients with a fatty filum and a conus medullaris in a normal position. The treatment of asymptomatic patients with conus lipomas remains a topic of debate that will not be resolved until the natural history of this disorder is more fully understood. We believe that prophylactic surgery in these cases can be done with low risk and may forestall or prevent the onset of symptoms, some of which may be irreversible once present, and we therefore recommend surgical intervention early after diagnosis. Regardless of the treatment path chosen, these patients are always at risk of retethering and delayed neurological deterioration; therefore, close monitoring by a multidisciplinary team of orthopedic surgeons, urologists, physical therapists, and neurosurgeons is important.

\section{References}

1. Anderson FM: Occult spinal dysraphism: a series of 73 cases. Pediatrics 55:826-835, 1975

2. Arai H, Sato K, Okuda O, Miyajima M, Hishii M, Nakanishi H, et al: Surgical experience of 120 patients with lumbosacral lipomas. Acta Neurochir (Wien) 143:857-864, 2001

3. Atala A, Bauer SB, Dyro FM, Shefner J, Shillito J, Sathi S, et al: Bladder functional changes resulting from lipomyelomeningocele repair. J Urol 148:592-594, 1992

4. Barolat G, Schaefer D, Zeme S: Recurrent spinal cord tethering by sacral nerve root following lipomyelomeningocele surgery. Case report. J Neurosurg 75:143-145, 1991

5. Bertorini T, Woodhouse C, Horner L: Muscle hypertrophy secondary to the tethered cord syndrome. Muscle Nerve 17: 331-335, 1994

6. Blount JP, Elton S: Spinal lipomas. Neurosurg Focus 10(1): E3, 2001

7. Brophy JD, Sutton LN, Zimmerman RA, Bury E, Schut L: Magnetic resonance imaging of lipomyelomeningocele and tethered cord. Neurosurgery 25:336-340, 1989

8. Brown E, Matthes JC, Bazan C, Jinkins JR: Prevalence of incidental intraspinal lipoma of the lumbosacral spine as determined by MRI. Spine 19:833-836, 1994

9. Bruce DA, Schut L: Spinal lipomas in infancy and childhood. Childs Brain 5:192-203, 1979

10. Brunelle F, Sebag G, Baraton J, Carteret M, Martinat P, PierreKahn A: Lumbar spinal cord motion measurement with phasecontrast MR imaging in normal children and in children with spinal lipomas. Pediatr Radiol 26:265-270, 1996

11. Byrne RW, Hayes EA, George TM, McLone DG: Operative resection of 100 spinal lipomas in infants less than 1 year of age. Pediatr Neurosurg 23:182-187, 1995

12. Carter CO, Evans KA, Till K: Spinal dysraphism: genetic relation to neural tube malformations. J Med Genet 13:343-350, 1976

13. Chapman P, Stieg PE, Magge S, Barnes P, Feany M: Spinal lipoma controversy. Neurosurgery 44:186-193, 1999

14. Chapman PH: Congenital intraspinal lipomas: anatomic considerations and surgical treatment. Childs Brain 9:37-47, 1982

15. Colak A, Pollack IF, Albright AL: Recurrent tethering: a common long-term problem after lipomyelomeningocele repair. Pediatr Neurosurg 29:184-190, 1998

16. Dias MS, McLone DG: Normal and abnormal early development of the nervous system, in McLone DG (ed): Pediatric Neurosurgery: Surgery of the Developing Nervous System, ed 4. Philadelphia: WB Saunders, 2001, pp 31-71

17. Dias MS, Schoenwolf GC: Molecular biology of early neural development, in McLone DG (ed): Pediatric Neurosurgery: Surgery of the Developing Nervous System, ed 4. Philadelphia: WB Saunders, 2001, pp 73-86

18. Ehni G, Love J: Intraspinal lipomas. Report of cases, review of the literature, and clinical and pathological study. Arch Neurol Psychiatry 53:1-28, 1945

19. Fone PD, Vapnek JM, Litwiller SE, Couillard DR, McDonald $\mathrm{CM}$, Boggan JE, et al: Urodynamic findings in the tethered spinal cord syndrome: does surgical release improve bladder function? J Urol 157:604-609, 1997

20. Foster LS, Kogan BA, Cogen PH, Edwards MS: Bladder function in patients with lipomyelomeningocele. J Urol 143: 984-986, 1990

21. Giudicelli Y, Pierre-Kahn A, Bourdeaux AM, de Mazancourt P, Lacasa D, Hirsch JF: Are the metabolic characteristics of congenital intraspinal lipoma cells identical to, or different from normal adipocytes? Childs Nerv Syst 2:290-296, 1986

22. Hall WA, Albright AL, Brunberg JA: Diagnosis of tethered cords by magnetic resonance imaging. Surg Neurol 30:60-64, 1988

23. Hansasuta A, Tubbs RS, Oakes WJ: Filum terminale fusion and dural sac termination: study in 27 cadavers. Pediatr Neurosurg 30:176-179, 1999

24. Herman JM, McLone DG, Storrs BB, Dauser RC: Analysis of 153 patients with myelomeningocele or spinal lipoma reoperated upon for a tethered cord. Presentation, management and outcome. Pediatr Neurosurg 19:243-249, 1993 
Spinal lipomas: clinical spectrum, embryology, and treatment

25. Hoffman HJ, Taecholarn C, Hendrick EB, Humphreys RP: Management of lipomyelomeningoceles. Experience at the Hospital for Sick Children, Toronto. J Neurosurg 62:1-8, 1985

26. Iskandar BJ, Oakes WJ, McLaughlin C, Osumi AK, Tien RD: Terminal syringohydromyelia and occult spinal dysraphism. J Neurosurg 81:513-519, 1994

27. James HE, Williams J, Brock W, Kaplan GW, U HS: Radical removal of lipomas of the conus and cauda equina with laser microneurosurgery. Neurosurgery 15:340-343, 1984

28. Johnson DL, Levy LM: Predicting outcome in the tethered cord syndrome: a study of cord motion. Pediatr Neurosurg 22: $115-119,1995$

29. Jones PH, Love JG: Tight filum terminale. AMA Arch Surg 73:556-566, 1956

30. Kanev PM, Bierbrauer KS: Reflections on the natural history of lipomyelomeningocele. Pediatr Neurosurg 22:137-140, 1995

31. Kang JK, Kim MC, Kim DS, Song JU: Effects of tethering on regional spinal cord blood flow and sensory-evoked potentials in growing cats. Childs Nerv Syst 3:35-39, 1987

32. Kannu P, Furneaux C, Aftimos S: Familial lipomyelomeningocele: a further report. Am J Med Genet A 132:90-92, 2005

33. Koen JL, McLendon RE, George TM: Intradural spinal teratoma: evidence for a dysembryogenic origin. Report of four cases. J Neurosurg 89:844-851, 1998

34. Kothbauer KF, Novak K: Intraoperative monitoring for tethered cord surgery: an update. Neurosurg Focus 16(2):E8, 2004

35. Krainer L: Die Hirn-und Rückenmarkslipome. Virchows Arch 295:107-142, 1935

36. Kulkarni AV, Pierre-Kahn A, Zerah M: Conservative management of asymptomatic spinal lipomas of the conus. Neurosurgery 54:868-875, 2004

37. La Marca F, Grant JA, Tomita T, McLone DG: Spinal lipomas in children: outcome of 270 procedures. Pediatr Neurosurg 26:8-16, 1997

38. Lassman LP, James CC: Lumbosacral lipomas: critical survey of 26 cases submitted to laminectomy. J Neurol Neurosurg Psychiatry 30:174-181, 1967

39. Loeser JD, Lewin RJ: Lumbosacral lipoma in the adult: case report. J Neurosurg 29:405-409, 1968

40. Long FR, Hunter JV, Mahboubi S, Kalmus A, Templeton JM: Tethered cord and associated vertebral anomalies in children and infants with imperforate anus: evaluation with MR imaging and plain radiography. Radiology 200:377-382, 1996

41. Lunardi P, Missori P, Ferrante L, Fortuna A: Long-term results of surgical treatment of spinal lipomas. Report of 18 cases. Acta Neurochir (Wien) 104:64-68, 1990

42. Maiuri F, Gambardella A, Trinchillo G: Congenital lumbosacral lesions with late onset in adult life. Neurol Res 11:238-244, 1989

43. McLendon RE, Oakes WJ, Heinz ER, Yeates AE, Burger PC: Adipose tissue in the filum terminale: a computed tomographic finding that may indicate tethering of the spinal cord. Neurosurgery 22:873-876, 1988

44. McLone DG: Lipomyelomeningocele repair, in McLone DG (ed): Pediatric Neurosurgery: Surgery of the Developing Nervous System, ed 4. Philadelphia: WB Saunders, 2001, pp 302-306

45. McLone DG, Naidich TP: Laser resection of fifty spinal lipomas. Neurosurgery 18:611-615, 1986

46. McLone DG, Naidich TP: Terminal myelocystocele. Neurosurgery 16:36-43, 1985

47. McLone DG, Thompson DN: Lipomas of the spine, in McLone DG (ed): Pediatric Neurosurgery: Surgery of the Developing Nervous System, ed 4. Philadelphia: WB Saunders, 2001, pp 289-301

48. McNeely PD, Howes WJ: Ineffectiveness of dietary folic acid supplementation on the incidence of lipomyelomeningocele: pathogenetic implications. J Neurosurg 100:98-100, 2004
49. Naidich TP, Fernbach SK, McLone DG, Shkolnik A: John Caffey Award. Sonography of the caudal spine and back: congenital anomalies in children. AJR Am J Radiol 142: 1229-1242, 1984

50. Naidich TP, McLone DG, Mutluer S: A new understanding of dorsal dysraphism with lipoma (lipomyeloschisis): radiologic evaluation and surgical correction. AJR Am J Radiol 140: 1065-1078, 1983

51. Naidich TP, Zimmerman RA, McLone DG, Raybaud CA, Altman NR, Braffman BH: Congenital anomalies of the spine and spinal cord, in Atlas SW (ed): Magnetic Resonance Imaging of the Brain and Spine, ed 2. Philadelphia: LippincottRaven, 1996, pp 1265-1337

52. Oakes W: Management of spinal cord lipomas and lipomyelomeningoceles, in Wilkins RH, Rengachary SS (eds): Neurosurgery Update II: Spinal, Pediatric, and Functional Neurosurgery. New York: McGraw-Hill, 1991, pp 3497-3504

53. Pang D: Sacral agenesis and caudal spinal cord malformations. Neurosurgery 32:755-779, 1993

54. Pang D, Wilberger JE: Tethered cord syndrome in adults. J Neurosurg 57:32-47, 1982

55. Paradiso G, Lee GY, Sarjeant R, Hoang L, Massicotte EM, Fehlings MG: Multimodality intraoperative neurophysiologic monitoring findings during surgery for adult tethered cord syndrome: analysis of a series of 44 patients with long-term follow-up. Spine 31:2095-2102, 2006

56. Pardanaud L, Luton D, Prigent M, Bourcheix LM, Catala M, Dieterlen-Lievre F: Two distinct endothelial lineages in ontogeny, one of them related to hemopoiesis. Development 122: 1363-1371, 1996

57. Peacock WJ, Murovic JA: Magnetic resonance imaging in myelocystoceles. Report of two cases. J Neurosurg 70:804-807, 1989

58. Pelissou-Guyotat I, Sindou M, Pialat J, Goutelle A: [Intramedullary mature teratoma associated with an attached cord and an intradural lipoma. Apropos of a surgically treated case. Review of the literature.] Neurochirurgie 34:205-209, 1988 (Fr)

59. Pierre-Kahn A, Lacombe J, Pichon J, Giudicelli Y, Renier D, Sainte-Rose C, et al: Intraspinal lipomas with spina bifida. Prognosis and treatment in 73 cases. J Neurosurg 65:756-761, 1986

60. Pierre-Kahn A, Zerah M, Renier D, Cinalli G, Sainte-Rose C, Lellouch-Tubiana A, et al: Congenital lumbosacral lipomas. Childs Nerv Syst 13:298-335, 1997

61. Raghavan N, Barkovich AJ, Edwards M, Norman D: MR imaging in the tethered spinal cord syndrome. AJR Am J Radiol 152:843-852, 1989

62. Rice JF, Jelsma RK: Combined arteriovenous malformation and intramedullary lipoma: surgery and embolotherapy. AJNR Am J Neuroradiol 7:171-173, 1986

63. Sathi S, Madsen JR, Bauer S, Scott RM: Effect of surgical repair on the neurologic function in infants with lipomeningocele. Pediatr Neurosurg 19:256-259, 1993

64. Sato S, Shirane R, Yoshimoto T: Evaluation of tethered cord syndrome associated with anorectal malformations. Neurosurgery 32:1025-1028, 1993

65. Scatliff JH, Kendall BE, Kingsley DP, Britton J, Grant DN, Hayward RD: Closed spinal dysraphism: analysis of clinical, radiological, and surgical findings in 104 consecutive patients. AJR Am J Radiol 152:1049-1057, 1989

66. Schneider SJ, Rosenthal AD, Greenberg BM, Danto J: A preliminary report on the use of laser-Doppler flowmetry during tethered spinal cord release. Neurosurgery 32:214-218, 1993

67. Schut L, Bruce DA, Sutton LN: The management of the child with a lipomyelomeningocele. Clin Neurosurg 30:464-476, 1983

68. Sebold CD, Melvin EC, Siegel D, Mehltretter L, Enterline DS, Nye JS, et al: Recurrence risks for neural tube defects in sib- 
lings of patients with lipomyelomeningocele. Genet Med 7:64-67, 2005

69. Seeds JW, Powers SK: Early prenatal diagnosis of familial lipomyelomeningocele. Obstet Gynecol 72:469-471, 1988

70. Selcuki M, Coskun K: Management of tight filum terminale syndrome with special emphasis on normal level conus medullaris (NLCM). Surg Neurol 50:318-322, 1998

71. Shian WJ, Chi CS, Wong TT: Lipomyelomeningocele: a 9-year review. Zhonghua Min Guo Xiao Er Ke Yi Xue Hui Za Zhi 35:57-62, 1994

72. Souweidane MM, Drake JM: Retethering of sectioned fibrolipomatous filum terminales: report of two cases. Neurosurgery 42:1390-1393, 1998

73. Stolke D, Zumkeller M, Seifert V: Intraspinal lipomas in infancy and childhood causing a tethered cord syndrome. Neurosurg Rev 11:59-65, 1988

74. Sutton LN: Lipomyelomeningocele. Neurosurg Clin N Am 6:325-338, 1995

75. Tani S, Yamada S, Knighton RS: Extensibility of the lumbar and sacral cord. Pathophysiology of the tethered spinal cord in cats. J Neurosurg 66:116-123, 1987

76. Taubner X: Zur Casuistik und Entwicklung der Hirnlipome. Virchows Arch Pathol Anat 110:95-101, 1887

77. Tortori-Donati P, Rossi A, Biancheri R, Cama A: Magnetic resonance imaging of spinal dysraphism. Top Magn Reson Imaging 12:375-409, 2001

78. Tortori-Donati P, Rossi A, Cama A: Spinal dysraphism: a review of neuroradiological features with embryological correlations and proposal for a new classification. Neuroradiology 42:471-491, 2000

79. Vade A, Kennard D: Lipomeningomyelocystocele. AJNR Am J Neuroradiol 8:375-377, 1987

80. Verga P: Lipomi ed osteolipomi della pia madre. Tumori 15: 321-357, 1929
81. Vernet O, O'Gorman AM, Farmer JP, McPhillips M, Montes JL: Use of the prone position in the MRI evaluation of spinal cord retethering. Pediatr Neurosurg 25:286-294, 1996

82. Virchow R: Ein Fall von Bosartigen, zum Teill in der Form des Neurons aufretenden Fettgeschwulsten. Virchows Arch Pathol Anat 11:281-288, 1857

83. von Koch CS, Quinones-Hinojosa A, Gulati M, Lyon R, Peacock WJ, Yingling CD: Clinical outcome in children undergoing tethered cord release utilizing intraoperative neurophysiological monitoring. Pediatr Neurosurg 37:81-86, 2002

84. Warder DE, Oakes WJ: Tethered cord syndrome and the conus in a normal position. Neurosurgery 33:374-378, 1993

85. Warder DE, Oakes WJ: Tethered cord syndrome: the low-lying and normally positioned conus. Neurosurgery 34:597-600, 1994

86. Wu HY, Kogan BA, Baskin LS, Edwards MS: Long-term benefits of early neurosurgery for lipomyelomeningocele. J Urol 160:511-514, 1998

87. Xenos C, Sgouros S, Walsh R, Hockley A: Spinal lipomas in children. Pediatr Neurosurg 32:295-307, 2000

88. Yamada S, Iacono R, Yamada B: Pathophysiology of the tethered spinal cord, in Yamada S (ed): Tethered Cord Syndrome. Park Ridge, IL: American Association of Neurological Surgeons, 1996, pp 29-45

Manuscript submitted May 15, 2007.

Accepted June 22, 2007.

Address reprint requests to: Marion L. Walker, M.D., Department of Neurosurgery, Division of Pediatric Neurosurgery, Primary Children's Medical Center, University of Utah, North Medical Drive, Salt Lake City, Utah 84113. email: marion.walker@ hsc.utah.edu. 